
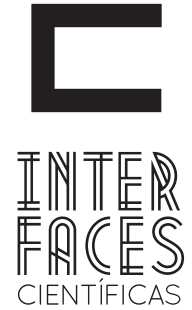

DIREITO

\title{
A LEGITIMIDADE DO ENTE PÚBLICO PARA PROVOCAR O CONTROLE JUDICIAL DAS DECISÕES DE SEU TRIBUNAL ADMINISTRATIVO TRIBUTÁRIO
}

João Guilherme Simões Herrera ${ }^{1}$

\section{RESUMO}

Analisa-se o efeito da decisão final administrativa dos tribunais e conselhos tributários, bem como a possibilidade do ente público ir a juízo buscar a anulação de decisão administrativa favorável ao sujeito passivo tributário, utilizando-se o método hipotético-dedutivo, tendo em vista a reabertura dos debates sobre o tema, em virtude de ações populares ajuizadas por um determinado cidadão, dizendo que o ente público foi omisso e seu conselho de julgamento fiscal cancelou débitos indevidamente. Concluiu-se pela possibilidade em determinadas condições.

\section{PALAVRAS-CHAVE}

Ente Público. Controle Judicial. Decisão Administrativa Tributária. 


\section{ABSTRACT}

An analysis of the effect of the final decision of the administrative tax courts, as well as the possibility of the public entity to go to judicial court seeking the annulment of administrative decision favorable to the taxpayer, using the hypothetical-deductive method, in order to reopening of discussions on the topic, because of class actions filed by a certain citizen, saying that the public entity was negligent and his tax court improperly canceled debts. It was concluded by the possibility under certain conditions.

\section{KEYWORDS}

Public Entity. Judicial Review. Administrative Tax Decision.

\section{INTRODUÇ̃̃̃O}

As Cortes Administrativas têm a função de conferir a legalidade dos atos administrativos, assegurando 0 contraditório e a ampla defesa, bem como os recursos a ela inerentes, em atendimento ao devido processo legal, nos termos do artigo $5^{\circ}$, inciso LV, da Constituição Federal de 1988.

Dentro deste contexto, na seara tributária, foram criados tribunais ou conselhos de julgamento administrativo a fim de conferir a legalidade ao lançamento de ofício questionado pelo contribuinte.

No Estado de São Paulo existe o Tribunal de Impostos e Taxas (TIT), vinculado à Coordenadoria de Administração Tributária da Secretaria da Fazenda. Trata-se de órgão paritário de julgamento, composto por representantes da Administração e dos contribuintes,

\section{RESUMEN}

En este trabajo se analiza el efecto de la decisión final administrativa de los tribunales y asesoramiento fiscal, así como la posibilidad de que la entidad pública a acudir a los tribunales para solicitar la anulación de la decisión administrativa imponible fiscal favorable, usando el método hipotético-deductivo, teniendo en ver a reabrir las discusiones sobre el tema, en virtud de las demandas colectivas presentadas por un determinado ciudadano, diciendo que la entidad pública fue negligente y deudas tributarias del consejo canceló el juicio de forma inadecuada. Se concluye por la posibilidad, en determinadas condiciones.

\section{PALABRAS CLAVE}

Entidad Pública. La Revisión Judicial. Decisión Administrativa Tributaria.

que tem por objetivo julgar os processos administrativos tributários decorrentes de lançamento de ofício, conferindo ao sujeito passivo da obrigação tributária o mais amplo exercício da defesa. 0 órgão de julgamento tributário na esfera federal é o Conselho Administrativo de Recursos Fiscais (CARF), que é órgão colegiado do Ministério da Fazenda de representação paritária de contribuintes e de representantes da Administração. O CARF tem por missão assegurar à sociedade a imparcialidade e celeridade na solução dos litígios tributários.

Os conselhos e tribunais administrativo-tributários existem na maioria dos Estados brasileiros e no Distrito Federal, mas o presente trabalho concentrará os exemplos do TIT paulista e do CARF, que possuem contornos semelhantes, a fim de delimitar e focar o estudo. 
Não há qualquer dúvida na doutrina ou na jurisprudência de que as decisões finais das Cortes Tributárias, de natureza administrativa, possam ser questionadas pelos contribuintes perante o Poder Judiciário.

Quando a decisão final na esfera administrativa mantém a exação fiscal, o sujeito passivo descontente pode impugná-la por meio de ação judicial. Geralmente é utilizada a ação anulatória para invalidar e extinguir o crédito tributário, admitindo-se, também, a impetração de mandado de segurança contra ato ilegal de constituição do crédito tributário indevido.

As opiniões se dividem, todavia, quando se almeja dizer que é possível ao próprio ente público buscar a invalidação do julgamento realizado por seu tribunal

\section{JURISDIÇÃO UNA VERSUS CONTENCIOSO ADMINISTRATIVO}

Os modelos de jurisdição adotados para controle dos atos administrativos variam entre o contencioso administrativo e o de jurisdição una ou única.

0 modelo do contencioso administrativo, também chamado de modelo francês, em razão de sua origem, tem o processo administrativo autônomo e insuscetível de reapreciação pelo Poder Judiciário. Decorre da teoria de Montesquieu acerca da absoluta separação de poderes. Nesse modelo, a seara administrativa é independente e faz coisa julgada material, não havendo a possibilidade de posterior busca pela anulação perante o Judiciário. 0 contencioso administrativo analisa os atos administrativos com exclusividade, excluindo-os da apreciação judicial. Há, portanto, uma dualidade: jurisdição administrativa e jurisdição comum.

O sistema de jurisdição una ou sistema inglês é aquele em que todos os litígios podem ser levados ou conselho administrativo na hipótese de decisão favorável ao sujeito passivo.

A questão fica ainda mais polêmica quando um cidadão, valendo-se da inércia do ente público, busca a invalidação do julgamento administrativo tributário por meio do Poder Judiciário.

Recentemente, em virtude do ajuizamento de inúmeras ações populares em face de decisões do CARF, a questão voltou aos holofotes.

Desta feita, o presente trabalho tem por objetivo analisar a possibilidade e a legitimidade do ente público, para buscar a tutela jurisdicional com o escopo de desconstituir decisões de seu próprio contencioso administrativo tributário.

ao Poder Judiciário, único competente para dizer o direito aplicável com definitividade. Nesse sistema, chama-se de jurisdição, tecnicamente, apenas aquela exercida pelo Poder Judiciário. É própria deste sistema a cláusula de inafastabilidade da jurisdição, ou seja, a de que todos os conflitos podem ser resolvidos pelo Judiciário em definitivo.

A utilização do sistema de jurisdição una não implica em vedar a solução de litígios na esfera administrativa. 0 que se assegura nesse sistema é que qualquer litígio pode ser levado ao Poder Judiciário. Desta feita, mesmo já havendo um processo administrativo em andamento ou concluído, é possível à parte descontente buscar a anulação e discutir a matéria perante o Poder Judiciário.

Este sistema de jurisdição uma, também, não impede que o controle de legalidade dos atos adminis- 
trativos seja feito pela própria Administração Pública, dentro da sistemática processual administrativa do ente. Essa competência é decorrente do poder de autotutela administrativa.

O sistema inglês ou sistema de jurisdição una foi adotado no Brasil, fazendo com que todos os litígios, inclusive os administrativos, possam ser submetidos ao Poder Judiciário para decisão definitiva. 0 princípio da inafastabilidade de jurisdição foi elencado de forma expressa no inciso XXXV do artigo $5^{\circ}$ da Constituição Federal de 1988. Trata-se de cláusula pétrea constitucional, não podendo ser modificada por emenda à Constituição.

Todavia, a adoção do sistema de jurisdição una não implica em dizer que no Brasil não se possa ter tribunais administrativos para solução de litígios entre o ente público e os administrados. A Administração Pública continua com o poder de controlar seus próprios atos. A diferença central é que as decisões administrativas não são dotadas de definitividade e podem ser submetidas à apreciação do Poder Judiciário.

Um contribuinte autuado pode, por exemplo, apresentar defesa da autuação tributária e manifestar suas razões na esfera administrativa. Terá, ainda, a possibilidade de recorrer da decisão de primeira instância administrativa, sempre com o objetivo de mostrar algum equívoco ou vício na autuação.

\section{PRINCÍPIO DA INAFASTABILIDADE DA JURISDIÇ̃̃O E A REVISÃO JUDICIAL DO ATO DE JULGAMENTO ADMINISTRATIVO}

Um primeiro e importante passo para solucionar a problemática proposta é verificar se o princípio da inafastabilidade da jurisdição, previsto no artigo $5^{\circ}$, inciso XXXV,
Os defeitos ou vícios do ato administrativo poderão ser reconhecidos na esfera administrativa, passando a ser desnecessário o processo judicial para a solução da lide já resolvida. Se, entretanto, for mantida a autuação, poderá o contribuinte ingressar com ação anulatória perante o Poder Judiciário, em face do ente público autuante, a fim de resolver em definitivo a questão. É importante frisar que somente a decisão final proferida pelo Poder Judiciário colocará fim à questão com força de coisa julgada.

Pode o administrado, ainda que tenha dado início à discussão na esfera administrativa, abandoná-la e buscar diretamente a solução do conflito por meio do Poder Judiciário.

Considera-se que há perda do interesse com relação ao processo administrativo quando o administrado busca, também, a medida judicial paralelamente. $\mathrm{Na}$ legislação do contencioso administrativo tributário paulista há norma expressa nesse sentido (artigo 30 , $\S 1^{\circ}$, da Lei $\left.n^{0} 13.457 / 2009\right)$, considerando que a busca pela solução na via judicial importa em renúncia ao direito de litigar no processo administrativo e desistência da solução administrativa.

A problemática reside na hipótese em que a Fazenda Pública pretende ingressar em juízo para reformar sua própria decisão administrativa, internamente definitiva, conforme se verá a seguir.

aplica-se, também, ao ente público ou se apenas representa uma garantia fundamental do indivíduo em face do Estado. Deve-se buscar saber a abrangência do citado princípio. 
“A lei não excluirá da apreciação do Poder Judiciário lesão ou ameaça a direito", é o que diz o dispositivo constitucional. Por estar situado no capítulo "Dos direitos e deveres individuais e coletivos", há vozes que defendem tratar-se de um direito do cidadão administrado, não do ente público. Seria, então, uma das garantias individuais de proteção do indivíduo contra o arbítrio estatal, não cabendo à Administração Pública invocá-lo contra os administrados.

Todavia, o argumento supracitado não se sustenta, uma vez que os entes federativos podem lançar mão de remédios constitucionais, tal como o Mandado de Segurança (inciso LXIX), previstos nesse mesmo capítulo. 0 direito de propriedade ali previsto, por óbvio, também é garantido aos entes públicos (inciso XXII), que, também, podem invocar direito adquirido, o ato jurídico perfeito e a coisa julgada (inciso XXXVI).

Embora o ente público represente o Poder Estatal, que deve ser contido a fim de evitar o arbítrio sobre o particular, e esta é a função da maior parte dos incisos do artigo $5^{\circ}$, não se pode olvidar a natureza de pessoa jurídica dos entes públicos, dotados, também, de direitos. 0 amplo e irrestrito acesso à jurisdição não pode ser negado ao próprio Estado. Ainda que se negue a possibilidade da Fazenda Pública ir a juízo questionar seu próprio ato, não é simplesmente dizendo que o amplo acesso à jurisdição não foi facultado aos entes públicos que se sustentará tal negativa.

A decisão final administrativa, na sistemática da jurisdição una (sistema inglês), não faz coisa julgada, sendo impróprio o termo "coisa julgada administrativa”. Ensina Meirelles (1997, p. 589) que “o que ocorre nas decisões administrativas finais é, apenas, a preclusão administrativa, ou a irretratabilidade do ato perante a própria Administração".

Mesmo sabendo que a decisão administrativa não faz coisa julgada e que o ente público, também, tem amplo acesso à jurisdição, parte da doutrina defende a impossibilidade da Fazenda Pública ir a juízo requerer a anulação da decisão administrativa de seu tribunal ou conselho por outros argumentos. Fundamenta-se tal posição, com relação ao processo administrativo federal, nos artigos 42 e 45 do Decreto $n^{0} 70.235 / 1972$, que tratam da definitividade das decisões administrativas e da exoneração do sujeito passivo da obrigação tributária quando a ele favorável, respectivamente.

Embora não tenham força de coisa julgada material, as decisões administrativas parecem ser vinculantes e imutáveis para a própria Administração, visto que ela própria já teria cancelado o débito e exonerado o sujeito passivo da obrigação tributária. Atuar em sentido contrário ofenderia a segurança jurídica e faria com que a existência do órgão de julgamento fosse absolutamente desnecessária. É o que defende Xavier (2001, p. 314). Diz-se, também, que haveria falta de interesse de agir em eventual ação anulatória promovida pelo próprio ente que exonerou administrativamente o sujeito passivo da obrigação tributária.

Machado (2002, p. 158) defende o seguinte:

\begin{abstract}
Admitir que a Administração Pública ingresse em juízo para questionar os atos do órgão de julgamento que a integra é admitir - um redobrado absurdo - que esse órgão de julgamento seja uma pessoa distinta daquela. O Estado, enquanto titular de direitos, é corporificado pela Administração Pública, conceito no qual encartam inclusive órgãos dos Poderes Legislativo e Judiciário, que não estejam no exercício das respectivas funções, legislativa e jurisdicional. É essa Administração, que é o próprio Estado como sujeito das relações jurídicas, que se coloca como sujeito das relações jurídicas. O Estado-Administração, por seu turno, pratica funções de controle de legalidade, por meio dos órgãos de julgamento administrativo. Não está, porém, exercitando função jurisdicional, no sentido de garantia constitucional segundo a qual nenhuma lesão ou ameaça de direito pode ser subtraída da apreciação do Judiciário. Só o Estado-jurisdição, corporificado pelos órgãos do Poder Judiciário, presta esta importante garantia. Assim, quando um órgão de julgamento administrativo decide um conflito entre o particular e Estado-Administração, é o próprio Estado, titular de relações jurídicas que está manifestando a sua vontade.
\end{abstract}


Entende-se que administração pública é uma coisa só e em razão disso o ente que decide manter um Tribunal Administrativo deve prestigiar suas decisões. Foi opção do legislador criar um contencioso administrativo tributário, para que a própria Administração efetuasse um controle interno da legalidade dos lançamentos tributários. Os julgadores não foram lá colocados somente para chancelar o lançamento, mas para decidir se este é correto, de acordo com sua convicção, baseados no Direito e nos fatos.

\section{Na mesma linha segue Harada (1999, p. 369):}

Não é dado à Administração Pública recorrer ao Judiciário para invalidar a sua própria decisão proferida, regularmente, em processo administrativo fiscal. No processo administrativo fiscal a Fazenda Pública é juiz e parte ao mesmo tempo [...]. Assim, atentaria contra o princípio da moralidade administrativa o fato de a Administração não querer se sujeitar à decisão que ela própria proferiu, no exercício regular de suas atribuições. Seria o mesmo que autodestruir o poder legalmente exercitado pela Administração, só porque resultou em uma decisão que é contrária aos seus interesses privados.

Imagine-se a absurda situação de inúmeras ações propostas a cada decisão do CARF, do TIT, do TCU, dos TCE, do CADE, favoráveis a particulares, com base na alegação de que a interpretação legal deve ser diferente ou que o entendimento jurídico deve ser diverso, forçando o Poder Judiciário a se manifestar sempre.

A posição em sentido contrário, que admite o questionamento judicial do julgamento administrativo favorável ao sujeito passivo, pela própria Fazenda Pública, tem por base a Súmula 473 do Supremo Tribunal Federal e o artigo 53 da Lei no 9.784/1999, que colocam como dever da Administração anular seus próprios atos, quando eivados de vício de ilegalidade.

Esta corrente permissiva também invoca o teor do artigo 156, inciso IX, do Código Tributário Nacional, que determina a extinção do crédito tributário somente quando há "decisão administrativa irreformável, assim entendida a definitiva na órbita administrativa, que não mais possa ser objeto de ação anulatória”. A leitura que se faz do inciso IX é no sentido de que só há a extinção em definitivo do crédito tributário após a decisão administrativa favorável ao contribuinte e após o decurso do prazo para a ação anulatória em face de tal decisão.

Com isso, o ato administrativo produzido pelos tribunais e conselhos de julgamento tributário poderia ser objeto de ação judicial com o escopo de anulá-lo. Se ao particular é concedida tal faculdade, pelo princípio da isonomia também mereceria igual tratamento o ente público.

Nesta linha, segue a argumentação de Brito (1999, 114-115):

O acesso ao Judiciário, como direito público subjetivo de ação, também, não poderia ser impedido à administração, apesar de ser tentadora a interpretação no sentido de que o disposto no inciso XXXV do art. $5^{\circ}$ da Constituição seria um direito fundamental do administrado e não da administração. Contudo, se prevalecesse essa interpretação, ela estaria em desacordo com o próprio sistema constitucional implantado entre nós que privilegia um princípio, o da isonomia, que se põe acima de todos os outros.

Segundo Alves (1999, p. 16 - 41), a possibilidade de questionamento judicial da decisão administrativa final, favorável ao contribuinte, dependerá das regras do processo administrativo tributário do ente. Se for admitido o recurso hierárquico ou a avocatória e a autoridade administrativa maior omitir-se de usar estes instrumentos, não poderá buscar o Judiciário para alterar a decisão administrativa. Todavia, se não houver a avocatória nem o recurso hierárquico, poderá a Administração buscar o Judiciário para discutir decisão final administrativa que the tenha sido desfavorável.

Em síntese, foi dito que se a decisão é final, dotada de definitividade dentro da Administração, cabe buscar o Judiciário para anulá-la. A decisão administrativa não pode ter contornos de imutabilidade, pois 
tal característica é afeta apenas às decisões judiciais transitadas em julgado e, ainda, depois de expirado o prazo da ação rescisória.

Para Pastorello (1999), há a possibilidade de a Administração pleitear perante o Poder Judiciário a anulação de uma decisão administrativa que tenha sido favorável ao contribuinte e decorrer de ilegalidade no julgamento, ou a decisão contrariar orientação uniforme do Plenário do Superior Tribunal de Justiça (STJ) ou do Supremo Tribunal Federal (STF), ou, ainda, ficar devidamente comprovado o desvio ético dos julgadores em benefício do contribuinte.

Assim, o que se defende não é a ampla e irrestrita busca pela revisão da decisão administrativa por mero descontentamento. Se assim o fosse, perderia o sentido da existência do contencioso administrativo tributário.

Embora não seja irrestrita e ilimitada, há a possibilidade de rever, por meio do Poder Judiciário, as decisões favoráveis aos sujeitos passivos que tenham sido julgadas em evidente ilegalidade, acarretando patente nulidade, assim como nos casos de decisão frontalmente contrária à orientação dos Tribunais Superiores, mormente neste momento de busca por efetividade e vinculação da orientação de tais tribunais. Quanto às decisões tomadas por desvio ético dos julgadores, acredita-se que não haja dúvida acerca de sua anulabilidade perante o Poder Judiciário.

Busca-se, portanto, abrandar a posição por vezes radical daqueles que não admitem o ingresso da Fazenda Pública em juízo para questionar a decisão de um tribunal ou conselho de julgamento tributário por ela própria constituído, sustentando a existência de coisa julgada administrativa ou de falta de interesse de agir.

Há, todavia, evidente interesse na anulação de atos lesivos, ainda que praticados por agentes públicos. A medida é adequada e necessária para a correção do ato que gera prejuízo ao ente público, desde que o fundamento não seja o mero inconformismo com a decisão administrativa, por divergência de interpretação de dispositivos legais, mas seja baseada em fortes argumentos de ilegalidade ocorrida no processo administrativo, de desvio ético do julgador ou, ainda, de decisão contrária à pacífica jurisprudência do STF e do STJ.

Nessa última hipótese, de contrariedade com a jurisprudência pacífica e consolidada dos Tribunais Superiores, o questionamento judicial da decisão, longe de importar em segurança jurídica, vem a defender a previsibilidade, a estabilidade e a segurança nas relações do Estado com o particular, além de garantir a isonomia entre os próprios contribuintes.

É de se imaginar que um determinado sujeito passivo deixe de questionar administrativamente um lançamento de ofício lastreado em jurisprudência tranquila dos tribunais superiores. Enquanto isso, outro sujeito passivo, em relação jurídica idêntica, com o simples escopo de protelar a constituição definitiva do crédito tributário questiona-o administrativamente e obtém decisão favorável, mas totalmente contrária à jurisprudência dos Tribunais Superiores. Nesse caso, é justo e necessário o processo judicial para buscar a anulação da decisão administrativa. Não seria absurdo dizer que, nessa hipótese, há desvio ético do julgador não comprovado, visto que não leva em consideração a interpretação do ordenamento jurídico dada pelos Tribunais Superiores pátrios.

É certo que as decisões dos Tribunais Superiores não podem ser ignoradas nos julgamentos administrativos. Ainda que não seja aplicada, a jurisprudência deve ser mencionada e deve ser exposto o motivo pelo qual não foi adotada a mesma linha de pensamento, seja mostrando a diferença entra a situação fática posta no processo administrativo e a julgada judicialmente (distinguishing), seja pela superação do precedente em razão do surgimento de novos argumentos (overruling).

Nesta linha, o Regimento Interno do CARF (Portaria $n^{0} 256$, de 22 de junho de 2009), em seu artigo 
62-A, determina que os conselheiros reproduzam no julgamento administrativo as decisões do STF e do STJ proferidas na forma dos artigos 543-B (que trata da repercussão geral) e 543-C (que trata dos recursos repetitivos) do Código de Processo Civil. Determina, ainda, que sejam sobrestados os julgamentos dos recursos administrativos nas mesmas hipóteses em que o STF sobrestar os recursos extraordinários cuja repercussão geral da matéria tenha sido reconhecida.

Esta norma sinaliza com clareza a influência das decisões dos Tribunais Superiores na solução da lide na fase administrativa. A tendência do processo moderno é uniformizar os entendimentos nas instâncias inferiores e na Administração Pública, de acordo com o que foi decidido pelos Tribunais Superiores, a fim de garantir a segurança jurídica.

No tocante à hipótese do ente público ingressar em juízo para anular o julgamento eivado de nulidade, pela prática de ilegalidade, pode ser evidenciada com um exemplo tirado do processo tributário administrativo do Estado de São Paulo. Prevê a Lei Estadual n ${ }^{\circ}$ 13.457/2009, em seu artigo 28, que é vedado afastar a incidência dispositivo legal, sob a alegação de inconstitucionalidade, salvo quando esta tenha sido proclamada com efeitos "erga omnes". Norma de semelhante teor há no artigo 62 do Regimento Interno do CARF (Portaria n² 256, de 22 de junho de 2009).
Qual atitude poderia ser tomada por um ente público que vê alguns de seus julgadores, sejam eles representantes dos contribuintes, ou seja, eles servidores públicos, afastando dispositivos legais sob a vaga alegação de inconstitucionalidade? Parece, aqui, ser possível buscar a anulação do julgamento administrativo que afronta o seu próprio regramento.

Frisa-se, por oportuno, que não se pode anular um ato administrativo sob o argumento de que houve erro na interpretação ou na aplicação da lei, desde que se tenha dado interpretação razoável e desde que não afronte jurisprudência pacífica de tribunal superior.

É prudente afastar, também, o argumento de que a constituição do crédito tributário estaria sendo feita pelo Poder Judiciário quando a própria administração ingressa com ação em face do julgamento administrativo. Para tanto, é necessário dizer que o lançamento de ofício já havia sido realizado pela autoridade pública competente no momento em que o sujeito passivo questiona administrativamente. Havendo decisão posterior, cancelando o lançamento de ofício, é essa decisão que será anulada pela via judicial. Anulando-se judicialmente a decisão que cancela o lançamento de ofício, não se pode dizer que o lançamento foi feito pelo Poder Judiciário. É óbvio que passará a vigorar o lançamento de ofício realizado pela autoridade competente.

\section{VENIRE CONTRA FACTUM PROPRIUM}

A doutrina civilista moderna trouxe a lume a máxima do "nemo potest venire contra factum proprium" como consectário da boa-fé objetiva, que significa a proibição do comportamento contraditório, ou seja, a vedação da atitude incoerente de agir contra os próprios atos.

Para Cordeiro (2001, p. 745), “venire contra factum proprium' postula dois comportamentos da mesma pes- soa, lícitos em si e diferidos no tempo. 0 primeiro - 'factum proprium' - é, porém, contrariado pelo segundo".

O princípio da segurança jurídica e a tutela da confiança fazem com que seja aplicada a proibição do "venire contra factum proprium" na relação do sujeito passivo de obrigação tributária com a Administração, em face de comportamento contraditório desta. 
A incidência da referida máxima à Administração implicaria em dizer, em princípio, que o ente público não pode questionar um ato seu perante o Poder Judiciário. É o que entende parte da doutrina. Rosa Junior (2006, p. 547) sustenta a proibição do comportamento contraditório no processo administrativo tributário, nos seguintes termos:

Assim, se a decisão administrativa for favorável ao sujeito passivo da obrigação tributária e não mais comportar qualquer espécie de recurso, tornando-se, portanto, definitiva, ocorrerá a extinção do crédito tributário. Não se esqueça que, no caso, a Fazenda Pública não poderá recorrer ao Poder Judiciário para rever sua própria decisão por força do princípio "nemo potest venire contra factum proprium".

Xavier (2001, p. 321) também segue nessa linha:

[...] não faria, na verdade, qualquer sentido que a Administração pública - que já é dotada do privilégio de praticar atos imediatamente executórios - e que é, além disso, obrigada constitucionalmente a exercer imparcialmente funções de autocontrole da legalidade dos seus atos mediante processo administrativo, baseado nos princípios de ampla defesa e do contraditório, pudesse rebelar-se contra decisões definitivas dos seus próprios órgãos judicantes, ou seja, 'venire contra factum proprium'.

A incidência do "nemo potest venire contra factum proprium" tem razão de ser e parece clara quando se diz que o ente público buscará alterar o entendimento de um de seus órgãos, por meio do Poder Judiciário por mero inconformismo, ou seja, por mera diferença de interpretação legal de dois órgãos diferentes da mesma pessoa jurídica.

Todavia, em hipóteses de evidente nulidade, de desvio ético, de nítida afronta à jurisprudência dos
Tribunais Superiores, verifica-se que o ato de julgamento administrativo representa a vontade da pessoa dos julgadores, não da pessoa jurídica. Aquele ato ilegal e nulo não pode ser imputado à pessoa jurídica, pois o julgador não estava a agir como um de seus órgãos quando do julgamento viciado. 0 comportamento contraditório não é de responsabilidade do ente público, mas apenas das pessoas físicas que realizaram o julgamento ilegal.

0 agente que extrapola os poderes que the foram investidos pela Administração, julgando além dos limites permitidos pelas normas do processo administrativo, ou em prejuízo da segurança jurídica, ou em desvio ético, age por si, não em nome do ente público que representa. Aqui também se faz um paralelo com a doutrina civilista, mas desta vez utilizando-se o conceito de "ultra vires" (artigos 47 e 1015 do Código Civil), segundo a qual o ato praticado fora dos poderes delimitados é nulo.

Deve-se frisar, todavia, que as normas que delimitam a atuação do órgão julgador devem ser colocadas de forma clara na regulamentação do processo administrativo fiscal, como foi feito no processo tributário paulista, em que se proíbe claramente o afastamento de lei com base em inconstitucionalidade não declarada pelo Supremo Tribunal Federal. Os julgadores que ignoram esta proibição e declaram inconstitucionalidades no julgamento administrativo, age claramente fora dos limites de poder que lhes foram atribuídos, razão pela qual o ato não pode ser imputado a pessoa jurídica e não pode ser aplicado o "nemo potest venire contra factum proprium" em ação judicial do Estado que busque anular o referido julgamento. 


\section{PARECER PGFN № 1087/2004}

A Procuradoria da Fazenda Nacional (PFN), através do Parecer PGFN no 1.087 , proferido em 19 de julho de 2004, causou polêmica e deixou ainda mais quente o debate sobre a possibilidade da Fazenda Nacional rever, em âmbito judicial, as decisões administrativas do CARF desfavoráveis à União.

A Portaria PGFN no 820, publicada em 29 de outubro de 2004, que "disciplina, no âmbito da Procuradoria Geral da Fazenda Nacional, a submissão de decisões dos Conselhos de Contribuintes e da Câmara Superior de Recursos Fiscais à apreciação do Poder Judiciário", normatizou a questão dentro da PFN, com base no referido parecer.

O entendimento exposto no parecer fundamenta-se, essencialmente, no principio da inafastabilidade da apreciação jurisdicional, situado no inciso XXXV, do artigo $5^{\circ}$ da Constituição Federal.

Embora tenha sido proferido de forma casuística, em decorrência de evento específico, o Parecer PGFN $n^{0} 1.087 / 2004$ acabou por dar contornos gerais à possibilidade de revisão judicial da decisão do CARF, a ser provocada pela própria PFN.

0 antecedente histórico que motivou o parecer, em apertada síntese, consistiu na lide entre um fundo de previdência privada e a União no tocante à imunidade do Imposto sobre a Renda (IR).

O fundo questionou administrativamente uma autuação fiscal e obteve decisão favorável do Conselho de Contribuintes. Por ser unânime a decisão, restou inviável o recurso do Fisco à Câmara Superior de Recursos.

A PFN interpôs, então, recurso hierárquico para o Ministro de Estado da Fazenda, visando à anulação da decisão, fundamentando as razões recursais em pacífica jurisprudência do Superior Tribunal de Justiça (STJ). 0 recurso foi admitido pelo Ministro da Fazenda, que determinou a intimação do contribuinte para apresentar contrarrazões. Inconformado, o fundo de previdência impetrou o mandado de segurança $\mathrm{n}^{\circ} 8810$ perante o STJ.

O Superior Tribunal de Justiça (2003) proferiu decisão, dizendo que a "competência ministerial para controlar os atos da administração pressupõe a existência de algo descontrolado, não incide nas hipóteses em que o órgão controlado se conteve no âmbito de sua competência e do devido processo legal". Disse, ainda, que

o controle do Ministro da Fazenda (Arts. 19 e 20 do DL 200/67) sobre os acórdãos dos conselhos de contribuintes tem como escopo e limite o reparo de nulidades. Não é lícito ao Ministro cassar tais decisões, sob o argumento de que o colegiado errou na interpretação da Lei. As decisões do conselho de contribuintes, quando não recorridas, tornam-se definitivas, cumprindo à Administração, de ofício, "exonerar o sujeito passivo dos gravames decorrentes do litígio" (Dec. 70.235/72, Art. 45).

Como se vê, afastou-se a possibilidade do Ministro da Fazenda, administrativamente, admitir a revisão do caso já decidido pelo Conselho de Contribuintes. As circunstâncias fáticas que resultaram na decisão do STJ deram ensejo à elaboração do Parecer PGFN nº 1.087/2004.

No referido parecer, defende-se a ideia de que o controle judicial das decisões de Conselhos de Contribuintes é possível em virtude do poder-dever de verificação da legalidade dos atos administrativos, bem como pelo princípio da inafastabilidade da jurisdição. Defende-se a possibilidade de invalidação judicial da decisão administrativa, seja pelo controle de legalidade, seja pelo controle de juridicidade, que é uma aferição de mérito.

Como instrumentos para a busca da invalidação dos julgamentos administrativos desfavoráveis, elenca o mandado de segurança, a ação de conhecimento de rito ordinário, a ação civil pública e a ação popular. 
Ao que parece, o parecer da PGFN abriu a possibilidade da União questionar judicialmente quaisquer decisões do atual CARF, por mero inconformismo, sob 0 argumento de controle da legalidade ou da juridicidade dos atos administrativos. A amplitude autorizada pelo parecer não conta com a concordância da maior parte da doutrina.

Silva (2004) diz que perderia sentido a existência do processo administrativo tributário, pois a grande vantagem de se discutir administrativamente é a possibilidade desta ser julgada por um corpo técnico de julgadores, cuja decisão final será definitiva se favorável ao contribuinte. A decisão administrativa, desde que fundada no exame da legislação e não em questões políticas e argumentos de cunho estritamente arrecadatório, deve prevalecer. Se assim não for, o processo administrativo certamente cairá no ostracismo.

Além de levar ao fim do processo administrativo tributário, o entendimento de ampla abertura de questionamentos judiciais acarretaria a propositura de uma enxurrada de processos judiciais.

Em exemplo recente, cerca de cinquenta e nove ações populares foram propostas pela esposa de um ex-procurador da Fazenda Nacional, em face de decisões do CARF, dizendo que o órgão "liberou" empresas de pagarem seus tributos. A alegação era de mérito, ou seja, afirma a autora que o lançamento fiscal estava correto e que a decisão administrativa final é incorreta. Chegou a incluir no pólo passivo, além da União e do contribuinte, os julgadores tributários, mas em emendas às iniciais optou por excluí-los posteriormente. 0 caso é emblemático e traz à tona novamente a questão ora em estudo. Em razão da problemática envolvida e do receio de novas ações, as sessões do CARF chegaram a ser suspensas e só foram retomadas após a Advocacia Geral da União assumir a defesa dos conselheiros que haviam sido incluídos no pólo passivo.
Boa parte das ações populares já foi julgada. Em algumas delas houve o indeferimento da inicial, por falta de interesse processual e inépcia, visto que a inicial não revelava qualquer ato lesivo ao patrimônio público, fazendo com que da narração dos fatos não decorra logicamente o pedido.

Decidiu-se que a ação popular não seria cabível para dizer qual tese jurídica seria melhor, sob o ponto de vista da autora, no tocante ao acórdão administrativo. O Ministério Público Federal, inconformado com as decisões judiciais, apresentou apelação nas ações extintas, defendendo que o mérito deveria ser apreciado, tendo em vista o princípio da inafastabilidade da jurisdição, bem como disse que não é possível haver no Brasil um contencioso administrativo "secundum eventum litis", ou seja, sendo admissível o acesso ao Judiciário se desfavorável ao contribuinte e obstado quando favorável.

Também, foi aventado na apelação ministerial que eventuais desvios no uso dos mecanismos colocados à disposição dos cidadãos devem, sim, ser coibidos, condenando-se o litigante de má-fé ao pagamento de honorários, despesas e ao décuplo das custas, mas a mera propositura de ação civil pública ou ação popular não pode deixar de ser incentivada quando não for proposta por um "improbus litigator".

Ainda que de forma superficial, o Procurador da República, após demonstrar claramente o interesse de agir, chegou a entrar no mérito da divergência entre a autoridade que lançou o tributo de ofício e os conselheiros que o cancelaram, mostrando o sentido da jurisprudência sobre o tema.

Caberia ao CARF, pelo menos, apresentar elementos suficientes para decidir contrariamente à jurisprudência dominante dos tribunais superiores, ou seja, deveria lançar mão do distinguishing ou do overruling.

Vê-se que a questão está longe de ser resolvida em definitivo. Por ora, aguarda-se o julgamento pelo Tribunal Regional Federal. 


\section{CONCLUSÃO}

Verifica-se que os elementos axiológicos em confronto na presente questão são princípio da segurança jurídica e o da proteção da confiança em face dos princípios da inafastabilidade da jurisdição (previsto no artigo $5^{\circ}, \mathrm{XXXV}$ da Constituição Federal), da legalidade, da moralidade e o da eficiência (artigo 37 da Constituição Federal).

Necessário se faz ponderar, caso a caso, a viabilidade da ação judicial a ser movida pelo ente público para anular o julgamento realizado em processo administrativo tributário.

O que não se pode é excluir amplamente a possibilidade de questionamento judicial das decisões dos tribunais ou conselhos administrativos tributários, nem dizer que todas as decisões administrativas são amplamente questionáveis por mero inconformismo de outro órgão do ente público.

\section{REFERÊNCIAS}

ALVES, José Carlos Moreira. Direitos Fundamentais do Contribuinte. In: XXIV Simpósio Nacional de Direito Tributário. São Paulo, 1999.

BRASIL. Superior Tribunal de Justiça. Mandado de Segurança $\mathbf{n}^{\circ} \mathbf{8 8 1 0}$, Relator Ministro Humberto Gomes de Barros, Diário da Justiça de 6 de outubro de 2003.

BRITO, Edvaldo. Problemas de processo judicial tributário. In: ROCHA, Valdir de Oliveira (Coord.). v. 3. São Paulo: Dialética, 1999.

CORDEIRO, António Manuel da Rocha e Menezes. Da boa-fé no direito civil. 2. ed. Coimbra: Almedina, 2001.
Os valores inseridos nos princípios supracitados não podem ser derrogados por outros, mas devem ser sopesados e aplicados de acordo com critérios razoáveis, de acordo com a ponderação casuística e de acordo com as evidências que o caso apresentar.

Assim, em determinadas hipóteses, como a de ilegalidade que acarrete nulidade do processo administrativo, a de julgamento contrário à jurisprudência pacífica dos Tribunais Superiores e a de julgamento com desvio ético, será possível ao próprio ente buscar a anulação do julgamento administrativo perante o Poder Judiciário, assim como, também, será possível que cidadãos o façam por meio de ações populares. Da mesma forma, os legitimados à ação civil pública também poderão atuar.

HARADA, Kiyoshi. Processo administrativo tributário. In: MARTINS, Ives Gandra (Coord.). Processo Administrativo Tributário. Pesquisas Tributárias, Nova Série, 5. São Paulo: RT, 1999.

MACHADO, Hugo de Brito. Algumas Questões do Processo Administrativo Tributário. In: MARTINS, Ives Gandra da Silva (Coord.). Processo Administrativo Tributário. São Paulo: Saraiva, 2002.

MEIRELES, Hely Lopes. Direito Administrativo Brasileiro. 22. ed. São Paulo: Malheiros, 1997.

PASTORELLO, Dirceu Antonio. Processo Administrativo Tributário. In: MARTINS, Ives Gandra da Silva (Co- 
ord.). Processo Administrativo Tributário. Pesquisas Tributárias, Nova Série 5. São Paulo: RT, 1999.

ROSA JÚNIOR, Luiz Emygdio F. da Rosa. Manual de Direito Financeiro e Direito Tributário. Rio de Janeiro: Renovar, 2006.

SILVA, Sérgio André R. G. da. Questionamento Judicial, pela Fazenda Nacional, de Decisão Administrativa Final - Análise do Parecer PGFN/CRJ nº 1.087/2004. Revista Dialética de Direito Tributário. São Paulo: Dialética, n. 109, outubro/2004.

XAVIER, Alberto. Do lançamento: teoria geral do ato, do procedimento e do processo tributário. 2. ed., Rio de Janeiro: Forense, 2001. 